\title{
Perception and Reality
}

\author{
Nadipuram R. Prasad
}

\begin{abstract}
The paper highlights a lifetime experience of knowledge gained through interactions with Professor Hung T. Nguyen and the profound impact he has made in advancing the state-of-the-art in modeling, simulating, and understanding the dynamics of uncertain systems. His seminal works on Random Fuzzy Sets have (a) significantly impacted our perceptions of seeking methods and approaches to acquire and assimilate data or information from uncertain sources, (b) enhanced our understanding to develop strategies for deep learning the interconnections, implications, and consequences, thereby allowing the processing of data to its logical conclusions and (c) has infinitely broadened the horizon towards conceiving machinebased decision-making architectures that optimize our perceived understanding to build systems that can mimic human decision-making capabilities. These three universal attributes fit the breadth and scope of Soft Computing. The paper focuses on three distinct topics wherein we explore human perceptions that merge the conscious attributes combining facts, myths, traditions, culture, beliefs, and a sense of reasoning towards a higher level of consciousness, and provides avenues for their adoption and physical realizations. The first topic discusses the possibilities of harvesting vast amounts of hydrokinetic energy from low-head flows in the Mekong Delta, Vietnam. The Mekong River has a perceived power potential of between 50 and 70 Gigawatts $(\mathrm{GW})$. The reality is only one-quarter of the perceived power is plausible for harvesting. We discuss the possibility of transforming existing concrete structures across the arteries and tributaries of the Mekong River in the Delta Region to mini-hydropower plants. One example shows the possibilities of harvesting up to $250 \mathrm{KW}$ at an existing structure that can serve the energy needs of local businesses involved in aquaculture, local commerce, and residential needs. Since recognizing conventional hydropower is ecologically damaging, Vietnam has focused its energy policy solely on Solar and Wind, which are 3-4 times higher in cost than Water. Low-head energy, which is currently unused, could be perceived as a significant
\end{abstract}

\footnotetext{
N. R. Prasad $(\bowtie)$

Klipsch School of Electrical \& Computer Engineering, New Mexico State University, Las Cruces, NM 88001, USA

e-mail: naprasad@nmsu.edu
} 
contributor to the renewable energy portfolio for Vietnam. The second topic discusses the possibility for Ayurvedic medicine, an ancient Indian practice of herbal medicine, as a complementary form of medication compared to modern medicine. The Tulsi plant is recognized for its life-saving properties that make Hindus believe it is a Holy plant. Scientific observations have shown the plant can produce substantial amounts of pure Oxygen by absorbing carbon dioxide from the ambient. Research has also shown that Tulsi can absorb fluorides from water. The discussions highlight the adoption of Ayurvedic medicine based on historical and traditional beliefs that Nature grown ingredients can induce natural body responses that aid in recovery from illnesses. Ayurvedic medicine exploits the power of the mind based on beliefs and traditions as a means for healing from illnesses. Finally, the third topic is a search for the meaning to the phrase "Pointing the finger at the Moon," and leading to the discovery of a three-dimensional holographic image on the Moon. The discovery sheds light on a long-standing question of what The Buddha was pointing to on the Moon. Historical background based on art is combined with basic Moon facts and a sense of geometry to uncover a three-dimensional holographic image that symbolizes Gautama Buddha's path to enlightenment. The form is identified as Abhaya Mudra, the Fearless Form. Among the many forms displayed in Buddhist sculptures of the meditation posture, the Abhaya Mudra is significant as it is a gesture for tolerance, fearlessness, and compassion. In Buddhist philosophy, the attributes of intolerance, fearfulness, and hatred are erased from the human mind through detachment.

\section{Keywords Perception $\cdot$ Virtual reality $\cdot$ Electric power $\cdot$ Ayurveda $\cdot$ Buddhist philosophy}

At the outset, it is an honor and a great privilege to write this paper honoring Professor Hung T. Nguyen for his immense contributions to the mathematical foundations of Random Fuzzy Set Theory, with applications to virtually anything imaginable that can be perceived and realized. His contributions are an ocean of knowledge that should motivate and inspire anyone in any discipline to explore and understand Life as a whole and the challenges towards meeting our professional goals and aspirations. If I could summarize what I learned from my deep engagements with Professor Hung Nguyen over three decades from a systems science perspective, it would be that "Everything in Life is fuzzy. Life is a continuum of actions and reactions. Reactions follow actions, and every reaction bears a consequence. There are reasons and motives for the consequences. Motives have aspirations. Aspiration is a perception of some future vision of the science, technology, and engineering needed to advance society. Virtual reality drives our perceptions. Perceptions of modelable and un-modelable uncertainty lead to realizations of robust systems."

In the age of high social interconnectivity and media interaction, there is a need to know relevant facts about everything past and present. It is essential to detect and disassociate false narratives. The future depends on the present. One might ask how facts can be preserved as pure facts and not as exaggerated facts, unless and until the root causes are uncovered. Our beliefs drive our perceptions that something could be 
true if it exists. The spectrum of possibilities ranges between mythological beliefs and the philosophy of science that overlaps with metaphysics exploring the nature of the human mind, ontology to study the existential possibilities, and epistemology in exploring the relationship between science and truth, and distinguishing between justified belief and opinion.

The publication of this paper ironically coincides with a momentous time in our history wherein our perceptions of normalcy has been suddenly disrupted. We fight the COVID-19 virus pandemic with a perception of discovering a vaccine soon enough to realize a sense of normalcy. The realities of finding a vaccine that is effective and will prevent acute infection is a temporal uncertainty. The discovery of an effective vaccine that can cure the disease is uncertain. The pandemic in its unpredictable ways has revealed a truth about the existential threat to Earth-an observable danger that is Physics-based. Shutdown and lockdown in Nations all across the globe to prevent the growth of infection have resulted in a significant drop in air pollution. Yet the perceptions of concerned scientists have little or no impact on those who believe otherwise and, therefore, Global Warming and Climate Change remains an issue.

\section{Understanding Perception and Reality}

As we look back in time, perceptions of the recent past are quite clear with little or no ambiguity, and which can be proven given that facts exist. Facts allow the backtracking of an event-sequence to the absolute truth. We can quote the exact words that someone spoke a hundred years ago in no uncertain terms with a high degree of specificity and certainty. Nearly a century ago, on January 27, 1921, Albert Einstein, in his address to the Prussian Academy of Sciences in Berlin on the topic of Geometry and Experience stated, "So far as the mathematics refer to reality, they are not certain. And so far as they are certain, they do not refer to reality." These statements reinforce the notions of impermanence and the theory of relativity and the degree to which mathematics can help humankind understand Life in its purest form.

Perceptions are mental formations based on the five senses for vision, hearing, touch, smell and taste, and a so-called sixth-sense that is a fusion of the five unique senses. Human perceptions are driven by facts, myths, traditions, customs, and beliefs, and a sense of reasoning that help to align the conscious attributes towards the desired vision. Recognizing that seeing is believing and that everything has a cause and an effect, one must see facts to assure the truth-value in decision making. Myths are unprovable and yet considered to be true in terms of cause and effect. We come to know about myths and practices during our upbringing and are conditioned to observe the conventions governing the myths. For instance, in Hinduism, each day of the week is associated with a specific Deity in the Hindu pantheon. The deep-rooted practice of Hinduism requires the observance of fasts and consumption of foods in a highly disciplined manner in commemoration of the deity worshipped 
each day. There are good days, and there are bad days for celebratory occasions. There is a good time of day and a bad time of day to conduct important daily chores. If you don't wear the sacred thread around your shoulder, then you are not a Brahmin. Scholars will argue the hidden powers behind these observances that can cause a metaphysical interaction between the soul and the higher being and allow one to achieve a transcendental state. It is the belief that one can be touched by a higher being and be granted one's wish in a paranormal state. Again, this is a belief, and one would dare not to refute this with a believer. The point is, myths exist, and superstitious belief has an overarching effect on everything. It is widely discussed and reported that political leaders of Nations consult with astrologers before making critical decisions. How and why planetary positions can influence the outcome of decision-making is in itself a deep-rooted belief that can neither be proven nor unproven, or disregarded.

Traditions transcend the sensation of touch, giving meaning to a feeling of closeness, a bond between entities, a mutual understanding of friendship, love, affection, gratitude, sympathy, and compassion. For instance, the culture to give flowers is a gesture of kindness and joy towards relatives and friends. The tradition is to offer a lotus flower arrangement as a heart-warming gift to someone you care and admire. Customs are analogous to the sweet smell of living within the confines of pleasure, comfort, and peace of mind. It is customary to place footwear at the front door-step to prevent outside dirt from entering the house. It is customary to bow in front of a deity with folded hands to receive the blessing from a higher entity. Customs induce moral values and respect for others. Belief lies in the understanding of the core values that speak the truth, and that whatever is written in the scriptures is true. Finally, the sixth-sense is a logical interpretation of all five sensory aggregates taken collectively. These perceptive attributes are clearly defined and described in canonical literature called the "Skandhas."

In Buddhist philosophy, the Sanskrit words "Pancha Skandha" translated as "five aggregates" sum up an individual's state of mind and physical existence." The five aggregates are (1) the environment, matter, body, shape, and form (rūpa, Avatār), which are the manifest form of the four elements - earth, air, fire, and water; it is a physical state that defines beauty and the individual persona and presentation. The Avatār epitomizes beauty, composition, and uniqueness of the shape and structure of everything in the Universe. It symbolizes the form of an object, which is living or inanimate. There is only one Planet Earth as we know and there is nothing like it anywhere we know so far, and NASA has named it the Blue Marble, a living and breathing object in Space. (2) Cognition, a state of thinking and building perceptions of things (samajñā), is a succession of thoughts that provide a clear sense for deductive reasoning, for grasping at the distinguishing features or characteristics of the object, and deep conceptual understanding. For instance, a river flowing from a higher elevation to a lower elevation with many waterfalls and fast-flowing waters has both potential and kinetic energy. It is a Physics-based conceptual understanding that can lead to the necessary mathematics and engineering. (3) Sensations, or feelings (vedanā), the urge to seek a greater understanding of the sensitivities and margins of pleasant, unpleasant, and neutral sensations that occur when our internal 
sense organs come into contact with external sense objects and the associated consciousness. What is good and acceptable for one may not be suitable and beneficial for the other. (4) Mental formations (samskāras), are planned and well thought out logical decision-making processes and connections, scenario-based decision-making clusters, and psychological forces that condition and spur mental activity. Mental formations are forces that shape moral and spiritual development through knowledge and insight. (5) Consciousness (vijñāna), the experience that brings together a greater understanding of perceived notions along with situational awareness and mindfulness towards those perceived notions. In short, the five aggregates, along with a sixth aggregate, a fusion of intuition, religious beliefs, and instincts, generate perceptions that lead to thinking, understanding, gaining knowledge, and raising the state of the conscious mind.

Increased awareness, according to the Skandhas, is an awakening. The practice of meditation is the type of training needed to achieve a higher state of the conscious mind. In principle, the human mind is a positive feedback system and is a characteristic that offers a glimpse into advances that can be made in deep learning and artificial intelligence. Whatever we wish to perceive exists somewhere, and in some shape and form. It is up to research, to uncover previously hidden facts, understand the effects and its possible implications, and create mental formations that allow us to perceive the realities in ways that reveal the truth and give rise to discovery.

With the Earth's precious environment in decline due to global warming and climate change, energy production and energy use must be moderated in ways that can sustain human civilization and bring economic growth and progress to the society. Methods to improve Earth's environment and processes for energy development must be explored simultaneously. Energy use no doubt will continue to rise as new cities and towns are born, communities grow, and small towns grow into large cities and explode amidst chaos and confusion due to overpopulation and overcrowded environment. With the year 2030 only a decade away, and Carbon emissions continuing to rise in India, China, and Vietnam, there is little chance that anything significant could be achieved within the next decade. Whether decarbonization will happen in the next two decades by the Year 2040 is doubtful despite efforts to reduce the use of fossil fuels by switching to Solar, Wind, and Water. Water is the cheapest resource among the three natural renewable energy sources. Large Solar and Wind power installations are 3-4 times more expensive and consume vast areas of land resources. The rate at which renewable energy resources are coming online is not fast enough to cause much change in the effects of global warming. Whether a noticeable shift in decarbonization will happen by 2050 remains pure speculation and a challenge for developers of renewable energy harvesting technology to conceive revolutionary ideas that are environmentally benign, and serve the energy needs efficiently.

While the perception that global use of renewable energy will peak by the Year 2050, the degree to which the perceived benefits will impact human society, in reality, remains uncertain. Both perception and reality are inseparable aggregates in our imaginative mind. One's perceptions and the realities in which the perceived attributes could materialize may be widely separated, and yet offer the possibilities for its realization. For instance, impressions of the Mekong River in terms of its total 
hydroelectric potential is over $50 \mathrm{GW}$, and some may say it is close to $70 \mathrm{GW}$. Size matters because it points to the immense amount of electric power that could uplift humanity in a giant leap. However, if all the perceived power were to be extracted, many more dams would be built across the Mekong River. Damming river flows would cause large reservoirs to drown out agricultural land, reduce the flows downstream, curtail fish migration, decimate mangrove forests, and destroy the ecosystem that supports aquatic and wildlife. Eventually, the entire ecosystem along the river would cease to exist. Impounding water upstream causes reduced flow downstream. Perceptions must, therefore, synchronize with the realities.

We choose to live within a realm of reality based on our imaginations and our own volition and understanding of what the environment offers. Deep thoughts, which probe the possibilities of existence, provide a level of fitness supporting the perception. Intuition is indeed a level of fitness. Something we had presumed to exist may be shown to exist if our hypothesis is correct, and hence, there exists a fitness function. For instance, gravitational waves, which Albert Einstein predicted must exist, were shown to exist. A massive Black hole at the center of the Milky Way galaxy that was known to exist was recently shown to exist. The LIGO-Virgo collaboration detected gravitational waves rippling out across space-time from the epic collision of two black holes from 2.4 billion light-years away. These are examples of how mathematics has influenced the development of technologies to discover Space and provide a better understanding of the structure of the Universe.

Human instincts to develop new technologies is motivated by the lack of existing resources to accomplish some desired objective adequately. It is uncertain if a technology that is commercially available today is suitable at a time when the conditions are not as previously anticipated. It may not work if the realities do not permit the use of the technology due to unpredictable uncertainties. A hydroelectric turbine developed for an irrigation canal where there are no fish cannot be used in a river where there is plenty of fish. Depth-of-perception could be a measure of the perceived reality. The more one focuses on the thought process, the more one learns and understands what the perception could mean and whether there is any truth in the perceived reality. The knowledge gained is a growth in our understanding of the physical laws that give the basic shape and form to the observed reality. It leads to a state of increased awareness of the perceived reality in the conscious mind. While the mathematics based on physical laws are exact, it excludes the realities that exist.

We need to explore the depths of human perception in ways that we may piece together our understanding of the reality in which our conscious attributes merge towards a higher level of consciousness. From an engineering viewpoint, perceptions of immensity and the potential of an immense body of water to serve human energy needs, for instance, must be realized in ways that appear not only reasonable at first glance, but lead to a location where exploration may follow. A bird's eye view motivates and inspires one to discover the ground-truth that exists and to find ways of exploring the ground-truth to align with a realistic vision.

During a road trip to the Mekong Delta, there was an urge to sense the immense amount of water in the Mekong River. It is the 12th largest river in the World. Short of taking an aerial view, the only option I had was to compare the size of bridges. From 

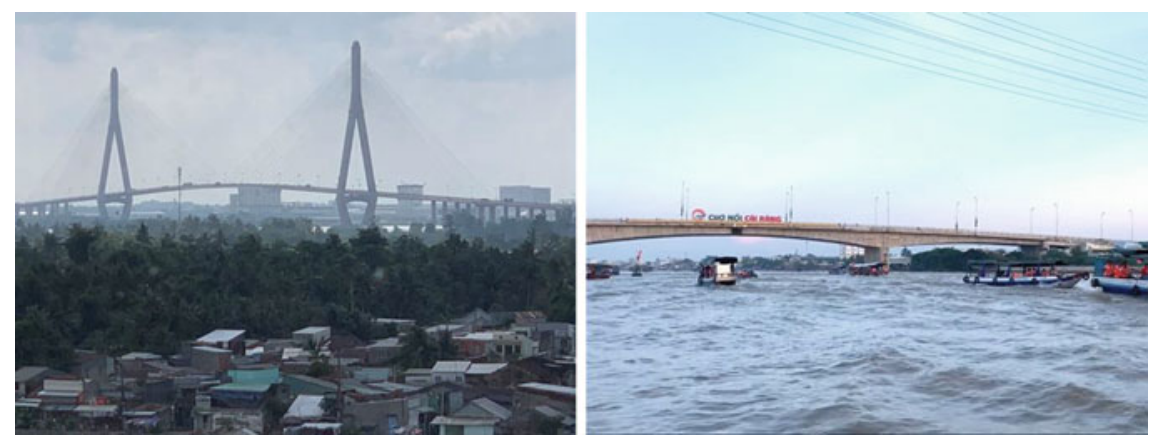

Fig. 1 A large bridge across the main branch of Mekong River and a small bridge across its tributary provides a perception of the immensity of the river and the enormous amount of unused kinetic energy

an engineering viewpoint, perceiving something big or small depends on the context of how and in what ways our perceptions potentially benefit society. Whether it is a large bridge or a small bridge that connects two landmasses, as illustrated in Fig. 1, the purpose of the bridge remains the same, namely, to allow the transportation of humans and material goods. However, what lies under the bridge may be perceived differently. The figure illustrates a large bridge across the main branch of the Mekong River and a relatively smaller bridge across a tributary. The relative sizes are indicative of the shore-to-shore width of the river at the respective bridge locations of the main branch and its feeder as it flows out into the South China Sea.

Philosophical interpretation leads to transformation in the mindset towards seeking the ground-truth. In research, a shared ideology when all else fails is to philosophize and seek an understanding of the ideal truths. Our perceptions at first appear impossible and unreachable. However, a seemingly impossible task, when made possible, is a breakthrough. The following examples serve to identify how perceptions can lead to realizations.

\section{Perceptions of Unused Low-Head Energy in the Mekong River}

Historically rivers have been the birthplace of civilizations and have an inseparable link with humans. With food and water readily available, rivers have served the critical needs of societies for centuries. Humans, therefore, have a natural bond with waterways as a natural energy resource. Rivers and streams from the high mountainous regions of Cambodia and Laos flow across Vietnam from the West to the East, creating low-head energy as the flow discharges into the South Sea and the Gulf of Thailand. Since recognizing that conventional hydropower is harmful to the ecology and is not a viable option, Vietnam has made little effort to explore the vast 

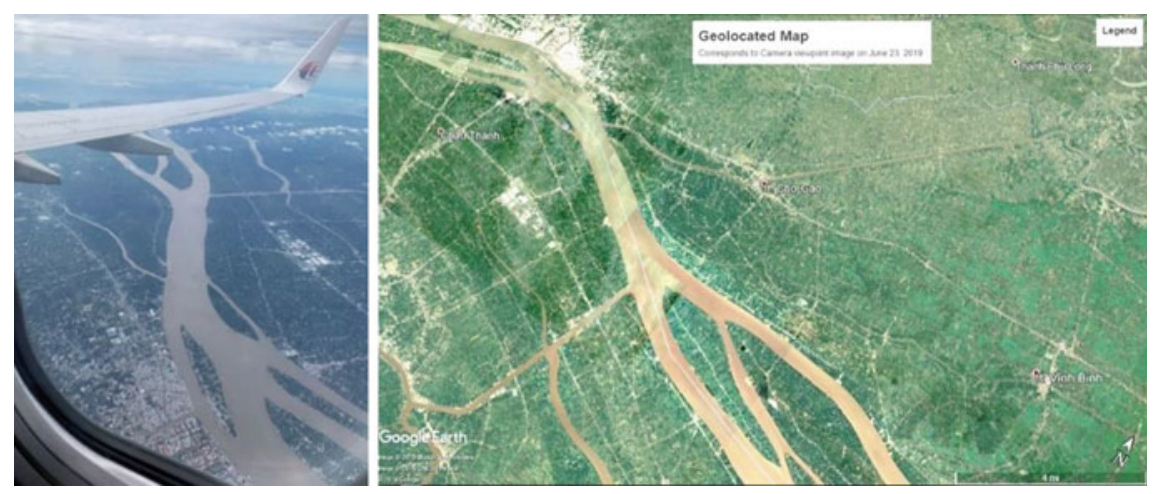

Fig. 2 Aerial view of the Mekong River on June 23, 2019, and co-located in Google Earth picture taken on January 1, 2019. Comparison points to perennial flows in the Mekong River

amount of unused low-head energy. Instead, the focus is on Solar and Wind energy. Low-head flows in the Mekong Delta offers immense amounts of hydropower to enable rapid growth in the Region's economy. The perception one can draw from a bird's eye view-point is that energy from the Mekong River alone could adequately serve the Delta Region while providing a path towards a Greener Vietnam. Yet many new coal-fired power plants are commissioned to meet the energy demands of the Delta Region. It is a dichotomy between our perceptions of clean air from Green energy and the realities driving economic growth. The cost to benefit ratio is reflected in one's perception to adopt the least cost technology that has the most benefit to society.

As luck would have it, on a flight from Kuala Lumpur, Malaysia, to Ho Chi Minh City, Vietnam, an aerial view of the Mekong River was awe-inspiring. Figure 2 illustrates the enormity of water flows, which would naturally increase during the monsoons and decrease during the off-season as it should.

The camera image shows river flows that are possibly enhanced by heavy monsoon rains upstream - a perception based on the knowledge of conditions that most likely exists during the monsoon season in the Lower and Upper Mekong River Basins of Laos and Cambodia. Co-located on a Google Earth image taken on January 1, 2019, one may infer from the relative size of the recent picture taken on June 23, 2019, that there are large quantities of perennial flows along the main arteries and tributaries.

A vast amount of electric power generation can be perceived along the entire length of the Mekong River. Flows in the Mekong Delta Region are along a low gradient due to the proximity of the South China Sea. As such, the flow velocity is low, but the discharge of water is large. Given that kinetic energy is one-half of the mass of water times the square of the flow velocity, it is easy to perceive the overall energy potential and the abundance of the natural renewable resource. If the flow-velocity is low, then an impeller placed along the axial length of the flow will also rotate at a low angular velocity. Coupled to gearboxes that convert low speed to 
higher speeds will enable effective power generation using commercially available generating equipment.

Novel approaches are needed to harness the vast amounts of unused low-head power, and we must seek out the methods through research and development. The following example shows in deterministic terms the amount of energy that could be harvested as a precursor to the engineering, design, and development of technology. The numbers reflect the magnitude and impact of producing large amounts of electric power from currently unused resources, and a basis for further exploration.

We take a look at one possibility in the Bach Lieu Province of the Mekong Delta, as an example, with the intent to transform an existing structure across the Bach Lieu River into a mini hydroelectric power plant. Figure 3 illustrates an existing concrete structure built across the river Song Bach Lieu, in the Bach Liew Province of the Mekong Delta. It serves as an example to perceive the possibilities for low-head hydropower generation at existing structures and to extend such perceptions at other similar structures along the river. The parameters are all based on visual observations.

The concrete structure allows water to flow through a gap approximately $20 \mathrm{~m}$ wide, $25 \mathrm{~m}$ deep, and $30 \mathrm{~m}$ long. By allowing $5 \mathrm{~m}$ depth for navigation purposes over the $30 \mathrm{~m}$ length, the available canal depth is $20 \mathrm{~m}$. With the effective canal dimensions, $20 \mathrm{~m}$ wide and $20 \mathrm{~m}$ deep and $30 \mathrm{~m}$ long, the cross-sectional area $A$ is $400 \mathrm{~m}^{2}$.
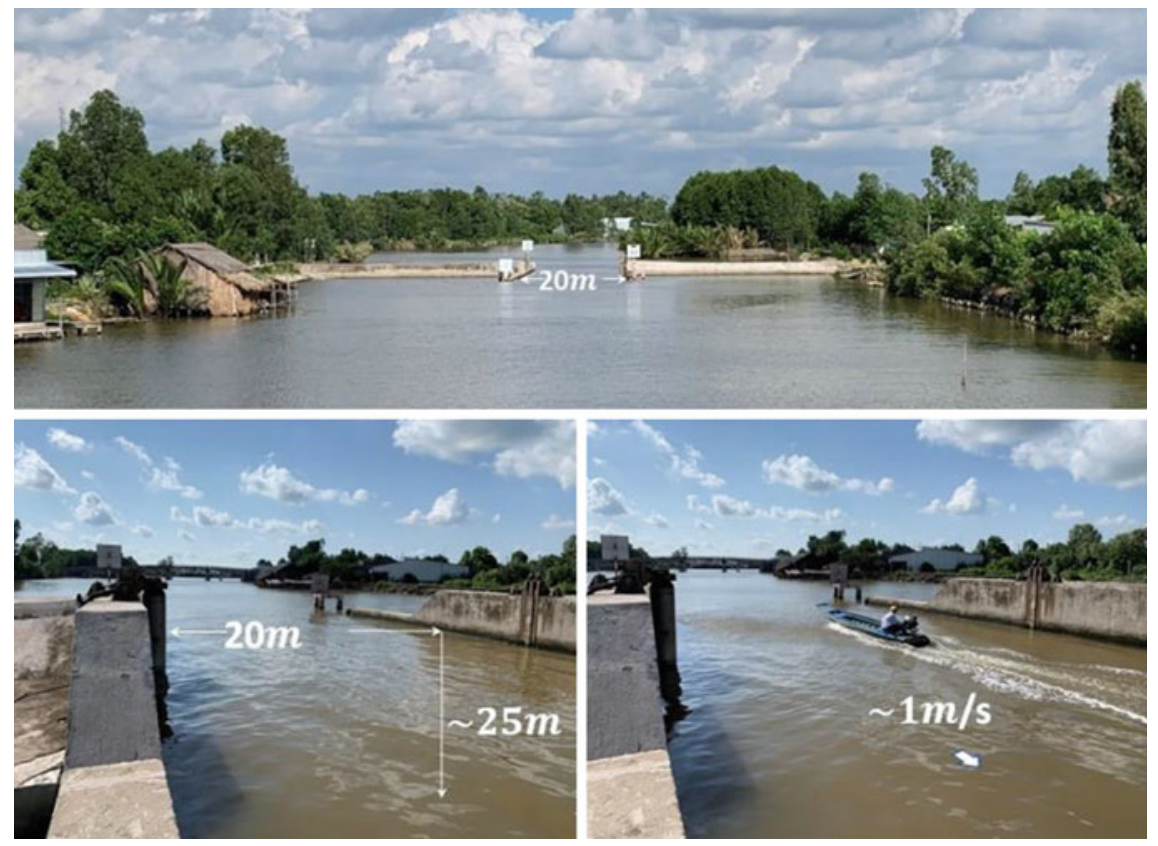

Fig. 3 Existing concrete structure across the Mekong River tributary Song Bach Lieu, Bach Lieu Province, Vietnam 
Fig. 4 Conceptual illustration of five low-speed impellers approximately $6 \mathrm{~m}$ apart

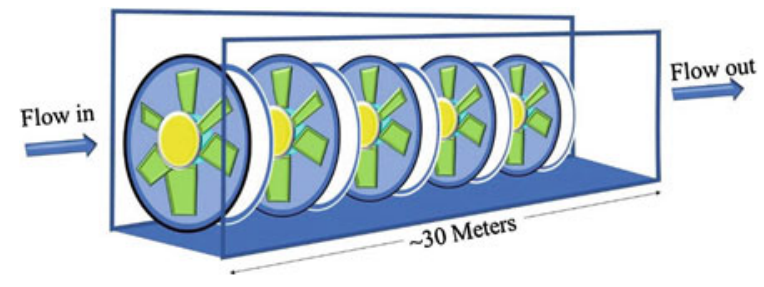

Based on a flow velocity $V$ of approximately $1 \mathrm{~m} / \mathrm{s}$, the discharge through the canal $Q=A V=400 \mathrm{~m}^{3} / \mathrm{s}$. With the density of water $\rho \approx 1000 \mathrm{~kg} / \mathrm{m}^{3}$, the kinetic power from one impeller shaft is computed as $0.5 \rho Q V^{2} \mathrm{~J} / \mathrm{s}$, which is equal to $(1000)(400)\left(1^{2}\right)=200,000 \mathrm{~W}$, or $200 \mathrm{~kW}$ per shaft.

If we assume five impeller shafts placed along the axial length of the canal, as illustrated in Fig. 4, we can perceive the hydropower potential as five times $200 \mathrm{~kW}$ or $1 \mathrm{MW}$.

The perception derived from a physical perspective points to the greater reality that a mass of water, about $400,000 \mathrm{~kg}$ in motion at a low velocity through the axial length of $30 \mathrm{~m}$, must transfer a large amount of kinetic energy. The estimate of $1 \mathrm{MW}$ is staggering. But this is precisely the outcome of laws that provide the perception for energy harvesting. The reality, however, is that the laws of Nature do not permit more than a quarter or perhaps one-third of the perceived estimate to extract. Therefore, one can believe that at a minimum, $250 \mathrm{~kW}$ can be harvested at this site to serve the local industries, businesses, and residential communities. The fact that there are many such concrete structures along Song Bach Lieu is highly encouraging towards perceiving the ground-truth for the potential low-head energy. Perception leads to innovation.

We turn now to something entirely different, where the belief in herbal medicine is gaining worldwide attention and transforming the mindset of societies towards health and wellness through herbal care.

\section{Ayurveda as an Alternative for Modern Health Care}

I recall as a kid learning to ride the bicycle, playing cricket, and playing soccer, and having frequent accidents on the playground, which caused bruises and, of course, pain. My mother would grind a special nut to make a paste and apply the paste to parts of the aching body and the injuries, and drink a little bit of the paste with warm milk to relieve the aching discomfort, and lo-and-behold the next day, I was good to go. The nut called Jaakai in India is none other than the nutmeg. Nutmeg is known to induce sleep and aid in the healing and recovery process. I recall using turmeric powder once to stop profuse bleeding from a deep cut. Turmeric is not only a disinfectant, but it is also a rapid coagulant. The same can be said about the treatment of colds and fever for which Ayurvedic medicine shows the ability to compete with modern 
medicine in terms of recovery from illness. There are many off-the-shelf products in modern pharmacy that offer the same or similar result but with the possibility for a reaction due to its synthesized chemical composition. It would be reasonable to perceive Ayurvedic medicine, therefore, as a complementary form of treatment to modern medical treatment based on evidence suggesting that there are indeed significant remedial benefits.

Unlike modern medicine that can have side effects due to chemical interaction, there are no side effects in Ayurvedic medicine because of natural ingredients and the absence of synthesized chemical compounds. The elements that comprise Ayurvedic treatment include the natural extracts of Nature grown herbs, tubers, roots, fruits, nuts, and plants that offer remedial comfort and relief to common illnesses. It is believed the combination of Yoga and Ayurveda can maintain the delicate balance between the mind, body, and spirit leading to health and wellness. Ayurvedic medicine is one of the World's oldest forms of holistic healing systems. Its primary purpose is to promote good health through healthy food and disciplined practice.

Among the many plants and herbs listed in the Ayurvedic apothecary, the Tulsi plant is considered a Holy plant by all Hindus because of its medicinal values, as described in Ayurveda, one of five Vedic scriptures in Hindu philosophy. An article in the Journal of Ayurveda and Integrative Medicine concludes "Modern-day scientific research into Tulsi demonstrates the many psychological and physiological benefits from consuming Tulsi and provides a testament to the wisdom inherent in Hinduism and Ayurveda, which celebrates Tulsi as a plant that can be worshipped, ingested, made into a tea and used for medicinal and spiritual purposes within daily life." [1]. Drawing a distinction between what we know today about the medicinal benefits of Tulsi, and how the human society may have first realized the potential for health and wellness leads one to perceive past reality and discover the truth. Modern science has shown that Tulsi plants produce Oxygen for $20 \mathrm{~h}$ every day while also producing Ozone for approximately $4 \mathrm{~h}$ every day. Maximum Oxygen production occurs at dawn and dusk when the humidity and dew point temperature are just right. Granted modern science with all the technology allows in-depth exploration that helps to understand the Chemistry of the Tulsi plant; there is no way of knowing exactly how people in the early days of civilization realized the benefit. It leaves one to speculate about the possibility that by observing the differences in health between those living close to the plants and those who were not, Tulsi was recognized to have remedial effects for those with breathing and pulmonary problems. Perceptions, therefore, that Tulsi could benefit those with pulmonary ailments can motivate and strengthen the willingness of people to adopt Ayurvedic medicine as a complementary form of treatment. Furthermore, the fact that the Tulsi plant produces large quantities of Oxygen by absorbing Carbon Dioxide from the air is particularly significant as it opens up the doors for widespread planting of Tulsi trees in parks, recreation centers, indoor terrariums, and greenhouses. Tulsi farming is already a big business venture that is primarily focused on marketing Tulsi tea. The Tulsi plant, therefore, appears to be an attractive solution for clean air and a clean environment.

Our beliefs are rooted in the customs and traditions of past realities that have withstood the test of time. The traditional practice in Hinduism requires one to 
accept "Theertham," water flavored with Tulsi leaves, as a blessing given to the devotee on behalf of the giver of knowledge, namely, the temple deity. No matter what, the core belief is that the theertham (water) is from the Holy River Ganges (although not true by any means), and is, therefore, readily accepted and consumed. The acceptance, based strictly on assuming the water is from the Ganges, is indeed blind faith. But having faith in religion is to have the willingness to put the power of the mind over matter towards healing and comfort, a belief that is engrained into the mindset. As such, the psychological response towards acceptance bears a direct effect on the physiological response as a consequence of one's belief. Scientific research shows Tulsi to drastically reduce the fluoride content in water due to its property of absorbing fluorides at a rapid rate and improving the taste of water. NASA intends to grow Tulsi plants in Space. The World Health Organization recommends a level of 0.5-1.0 part per million of fluorides in water that is safe for human consumption. Knowledge of all these facts tends to strengthen the belief and create a mindset for positive change. The perception, therefore, that Tulsi is indeed a miracle plant is believable. It is incredible to note that although ancient civilizations did not know the scientific facts as we know it today, they developed a deep bond with Nature in ways we in the present day are only left to imagine and speculate by perceiving the past and its realities as it existed then and establish pathways into the future.

There are no limits to one's imagination and creativity and no limits to what we can explore. Knowledge of facts is a driving force for the curious mind to study, understand, and investigate. If there is a question that begs an answer, we must find it. It does not matter where, when, or what. It is Why? We now turn to a discovery made in late 2007 and was reported in a blog under a pseudonym. ${ }^{1}$ It is reported here for the first time in a formal presentation.

\section{Pathways to Discovery}

It is reasonable to expect a discovery of something every minute somewhere around the globe. NASA discoveries are bountiful in that constant observation of deep Space is bound to acquire new information about the structure and formation of the Universe. Seeing is believing. So how do we discover that which we cannot readily perceive? Something hidden behind the scenes and waiting to be discovered.

Perceptions of ancient historical facts are difficult to correlate. One has to accept the facts based on religious beliefs and unconditional acceptance of the truth as written in scriptures and ancient classical art. We can assume with a high level of confidence, the literary translations of ancient canonical texts are as accurate as can be. The circumstances under which these facts were generated form a basis to understand the present, and perceive the future. Our perceptions of the present are influenced by the effects and consequences of the past. While historical events dating

\footnotetext{
${ }^{1}$ http://sun-faced-buddha-moon-faced-buddha.blogspot.com/2011/08/discovery-of-buddha-form. html.
} 
back over 2,600 years can be recounted with a level of certainty that the events did occur, the actual periods when the events occurred remain fuzzy and uncertain. The date and the period when events took place is based on scriptures and literary art, which may also be further supported by assertions embedded in the strictest customs and traditions that civilizations have observed, followed, and practiced throughout history. Religion and religious beliefs have withstood the test of time since their origins. Teachings from The Bhagwath Gita, The Bible, and The Koran are etched into the core beliefs of more than 7 billion humans on Earth.

The historical Buddha was a human who attained enlightenment approximately two thousand six hundred years ago. The UNESCO World Heritage Center has estimated the birth as $623 \mathrm{BCE}$, although there is a debate that he may have born sometime between 680 and 560 BCE. At the age of 29, he departed from his privileged life to seek answers to overcome human pain and suffering. His spiritual enlightenment paved a path to Nirvana, a transcendental state of mind devoid of pain and suffering, desires, and anger. He lived until the age of 80 . These are facts.

Teachings of The Buddha appear in scriptures written in the Pali language, a derivative of Sanskrit. It is said that Gautama Buddha attained enlightenment following 49 days of intense meditation. Plate 1 depicts Buddha's first sermon to his five disciples in the presence of Gods and demi-Gods on the first full moon night following His enlightenment. Murals depicting the life and death of Gautam Buddha are displayed in every monastery, Pagoda, and Buddhist temple across Asia.

There is a vast body of literature that supports the belief that on His path to spiritual enlightenment in a deep meditative state, Gautama Buddha had to overcome all obstacles posed by Mara, the King of evil. Mara is an ideal personification of five deadly characters that could induce chaos, create deception, perform vile acts, exert cruelty, and cause death in one's personality and drive them into Hell ${ }^{2}$ [2]. He attained a state of Nirvana, having detached himself from the clutches of attachment

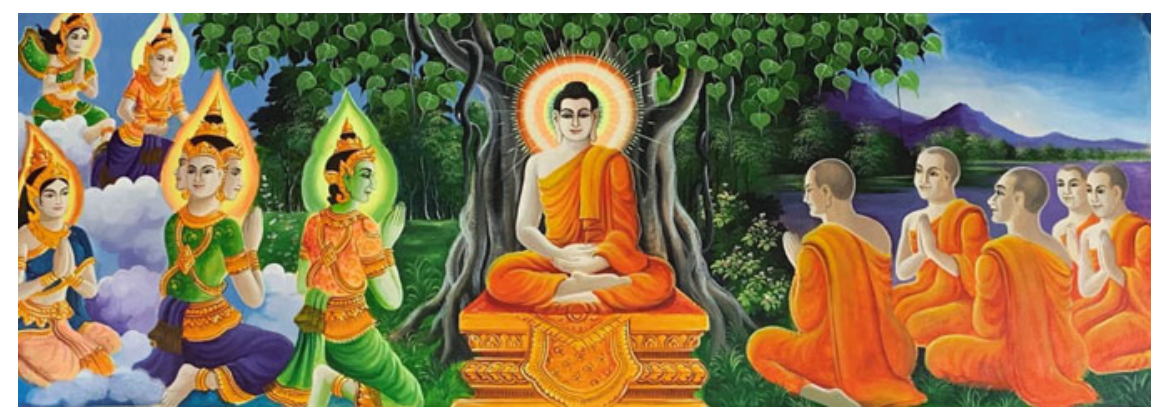

Plate 1 Gautama Buddha's first sermon following His enlightenment, Bach Lieu Pagoda, Bach Lieu Province, Vietnam, July 14, 2019

\footnotetext{
${ }^{2}$ The notions of decision-making in the human mind can be described as a competition between a rational mind and an irrational mind. At no cost will the rational mind accept the irrational mind. There is only one winner and that's the rational mind. Mara is synonymous to irrational mind.
} 
and desires. He had found a way of achieving a transcendental state of mind where there is no pain nor suffering, no desires or a sense of self, and the subject is released from the effects of prior sins (karma) and the cycle of death and rebirth. Nirvana is the final goal of Buddhism.

Legend has it that Mara's two daughters transformed into nymphs and unsuccessfully attempted to disrupt his focus and concentration through seduction and other vile acts. Mara himself transformed into five evil forces attacking Gautama's mind in every possible way, creating chaos, deception, engaging in despicable acts, demonstrating anger and cruelty and death. Plate 2 depicts The Buddha in a posture referred to as Abhaya Mudra (fearless form) when confronted by Mara. The large mural painting from Bach Lieu Pagoda in the Mekong Delta vividly portrays hostility, cruelty, violence, and death posed by Mara, and courage, love, compassion, peace, and harmony displayed by The Buddha.

The guiding principles of Buddhism are tolerance, mindfulness, and compassion attained through detachment. Tolerance induces patience and confidence, and a sense of fearlessness and courage to face odds and challenges. Mindfulness and compassion bring out one's sense of sharing, caring, giving, and empathy towards the well-being of others. These principles are firmly rooted in what is called Mudras. ${ }^{3}$ Mudras are symbolic hand gestures that channel the internal energy towards desired outcomes in the state of mind. The five principle hand gestures that sculptures of the Buddha show in meditation postures represent the Wheel of Dharma, touching the Earth, charity, compassion, and boon-granting, and the fearless form. Statues of The Buddha in Abhaya Mudra posture, similar to Fig. 5, appear everywhere in Southeast Asia.

Historically, the Moon has been admired for its celestial beauty and is the center of attraction for all things considered beautiful in time immemorial. Literary pieces

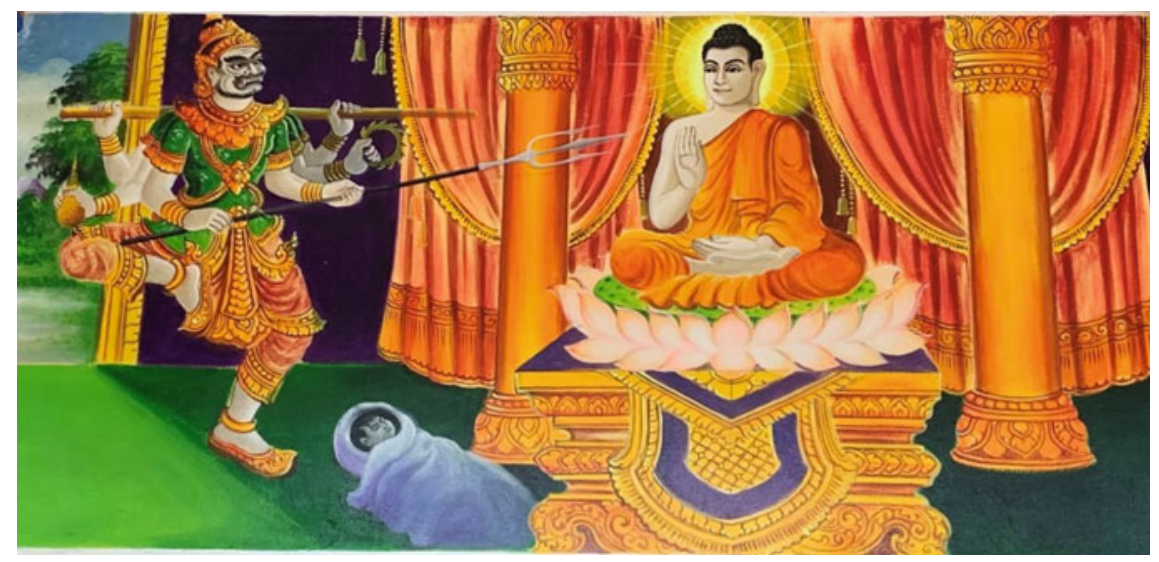

Plate 2 Mural of The Buddha in a calm and peaceful state amidst the threat posed by Mara. Bach Lieu Pagoda, Bach lieu Province, Vietnam, July 14, 2019

\footnotetext{
${ }^{3}$ Mudras of the Great Buddha: Symbolic gestures and postures. https://web.stanford.edu/class/ history $11 \mathrm{sc} / \mathrm{pdfs} /$ mudras.pdf.
} 


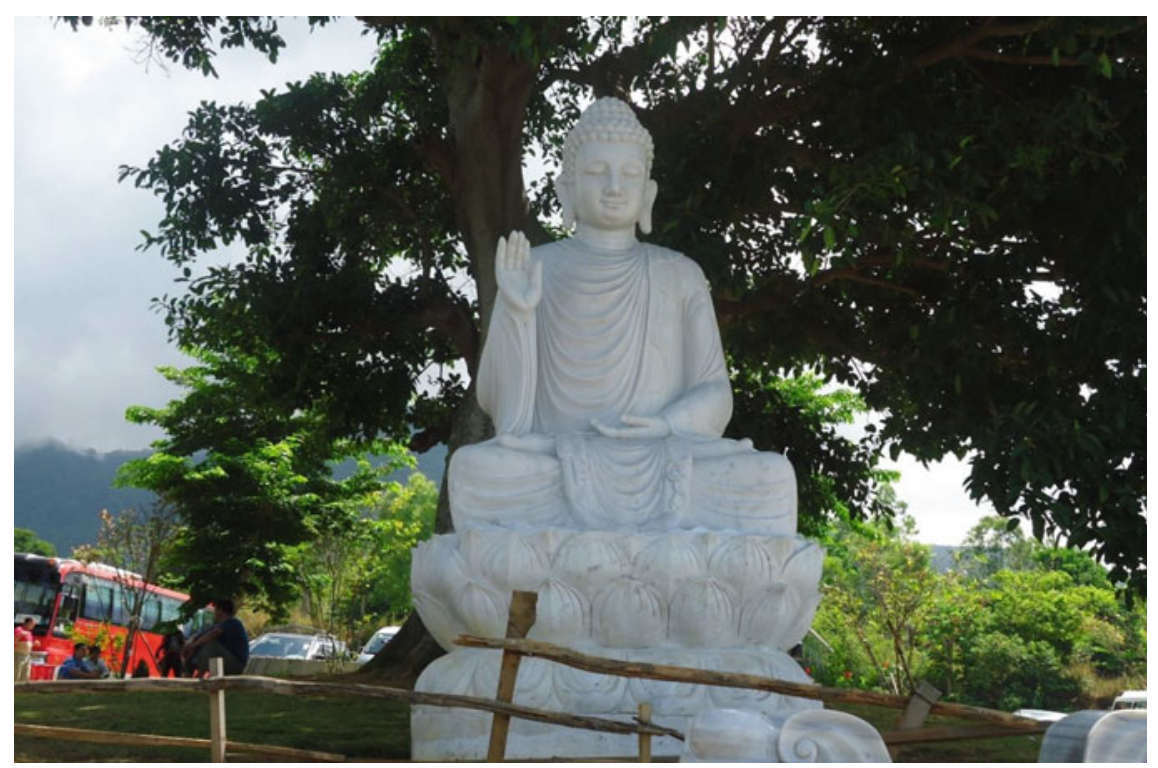

Fig. 5 Buddha statue at the Truc Lam Monastery overlooking Da Nang Bay in Vietnam shows the Abhaya Mudra form

of art portray the Moon as a mirror for all humanity on Earth. The synergy in the Earth-Moon relationship is overwhelming because while the Earth is rotating, the Near Side of the Moon is continuously facing Earth. It is analogous for all Earthlings to looking into a mirror and asking who we are? The Full Moon night is celebrated in the Asian culture for its historical role honoring the Harvest Moon and family togetherness.

Attracted by gravitational force, Earth and Moon rotate along their axes in the anticlockwise direction as they orbit the Sun. The geometrical positions are such that only half the Moon's spherical surface, referred to as the near-side, is always facing Earth. Considering the libration of the Moon, which is a swaying phenomenon of the Moon as it orbits the Earth, nearly 59\% of the Moon's surface is visible from Earth. The period of waxing towards a full Moon and then waning towards a new Moon is characterized by the Moon phases when the Moon exits from the shadow of Earth and then reenters, giving a cycle of motion that can be calculated precisely. Kepler's Laws of planetary motion accurately describe the positions of Earth and Moon around the Sun. There is no ambiguity in the Earth-Moon planetary motion around the Sun.

The Bhava-Chakra (Life-Circle), or the Circle of Life, is the epitome of Buddhist philosophy. ${ }^{4}$ It is a symbolic representation of the three poisons, namely, ignorance, attachment, and aversion, that can lead one along a path of self-destruction. It is

\footnotetext{
${ }^{4} \mathrm{~A}$ concise summary of the various elements of the Bhavachakra appears in https://www. glensvensson.org/uploads/7/5/6/1/7561348/wheel_of_life.pdf.
} 


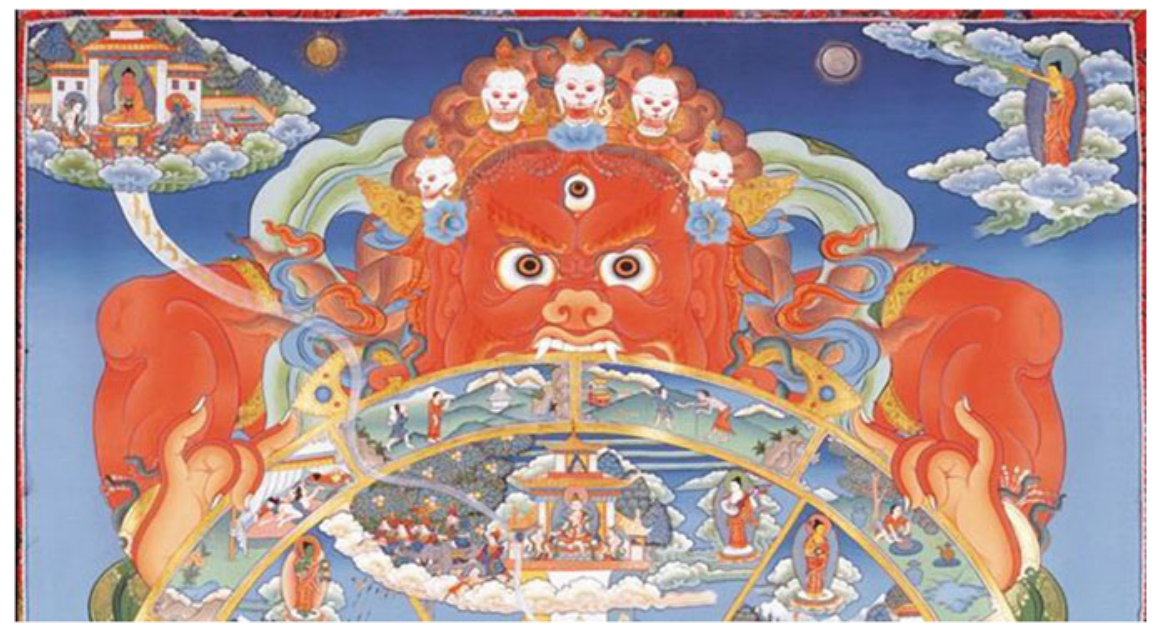

Plate 3 The top portion of the Bhavechakra shows on the right Buddha pointing to the Moon. Mars is at the top left. With both hands, Mara, the embodiment of evil, holds the Circle of Life, the disc representing impermanence (symbolism of the Moon). The representation on the left upper corner is a state of Nirvana where one is freed from all sins

said that The Buddha himself created the first depiction and passed it on to King Rudrāyaṇa, who, after studying the drawing, was enlightened.

Plate 3 illustrates only the top segment of the Bhavachakra from a 5th Century Tibetan wall painting to highlight the key characteristics that are useful in seeking an answer to what Buddha was pointing to on the Moon. Scholars interpret the image of The Buddha pointing toward the moon as the path to liberation.

Like modern published works that have a title, an abstract, and the details of work, the layout of the Bhavachakra may be described similarly. The symbolic abstract of the Bhavachakra is indeed Buddha pointing his finger at the Moon. ${ }^{5}$ Buddhist paintings depicting the root causes of human pain and suffering were recreated by word-of-mouth descriptions and through the words of Bodhidharma and the Bodhisattvas, followers, and messengers of The Buddha. They propagated Buddhist teaching throughout Southeast Asia.

When the Buddha gave his first sermon to his disciples on the first Full Moon night following his enlightenment, He explained his enduring struggles with Mara during his path to Nirvana. Legend has it that while pointing to the Moon, he said if one wishes to seek the truth, one must see where the truth is.

Plate 4 shows a Tibetan art icon from early 1st Century AD with Gautama Buddha pointing his finger at the Full Moon. The artist appears to have sketched an object on the Moon that is either a buffalo or an antelope. Growing up as kids, adults pointed

\footnotetext{
${ }^{5}$ The gesture of pointing to the Moon is very suggestive. The gesture does not proclaim anything except for one to look at the Moon and unravel the truth. What should one expect to see? It cannot be anything ordinary. Rather, it must be extraordinary. The expectation should be nothing short of a revelation. But what is it? We explore further.
} 


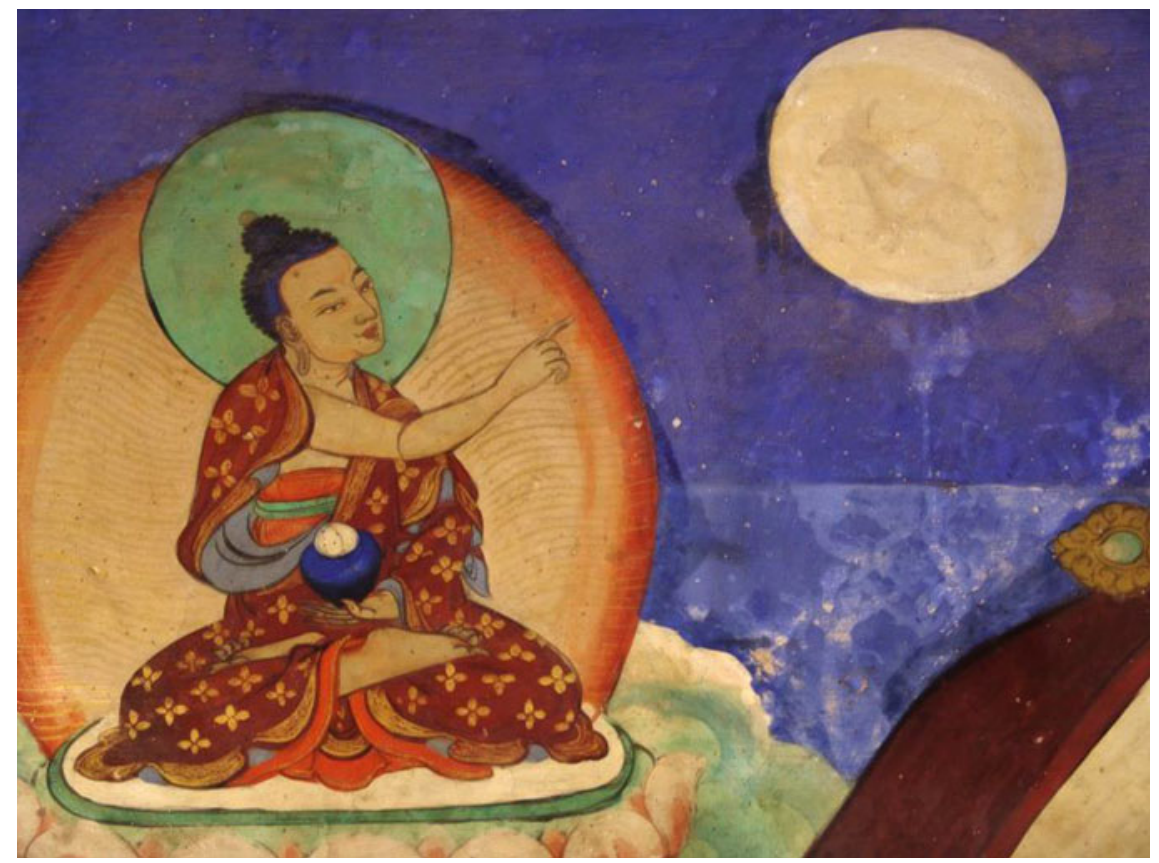

Plate 4 A 1st century AD Tibetan wall painting depicts the famous gesture of "Pointing the finger at the Moon." The message is suggestive of the fact that there is something extraordinary on the Moon. What can it be?

to the Moon and asked if we see a Rabbit on the Moon. The Internet is abuzz with tracings of outlines that separate the dark and bright regions of the Moon. ${ }^{6}$ Therefore, what appears on the Moon is unknown. So, what did Buddha point to on the Moon? What is the message to humanity in pointing to the Moon?

Since anything is possible, it is possible that in pointing to the Moon, Gautama Buddha described the existence of symbolic representations of life on Earth. Some image objects of life are in plain view. However, these are synonymous with trinkets one would find in a jewelry store while the most priced jewel remains hidden somewhere. One image that stands out is the notion of a family is quite striking as Fig. 6 illustrates the understanding of togetherness and the concept of family (samsāra).

In his seminal paper on the mathematical theory of communication theory [3], Claude Shannon states, "The fundamental problem of communication is that of reproducing at one point either exactly or approximately a message selected at another point. Frequently the messages have meaning; that is, they refer to or are correlated according to some system with certain physical or conceptual entities." What did Shannon imply by decoding information either exactly or approximately? Every message has a meaning. So, what is the message? The question is really what The

${ }^{6}$ Caricature images http://wfmh.org.pl/thorgal/Moon/. 

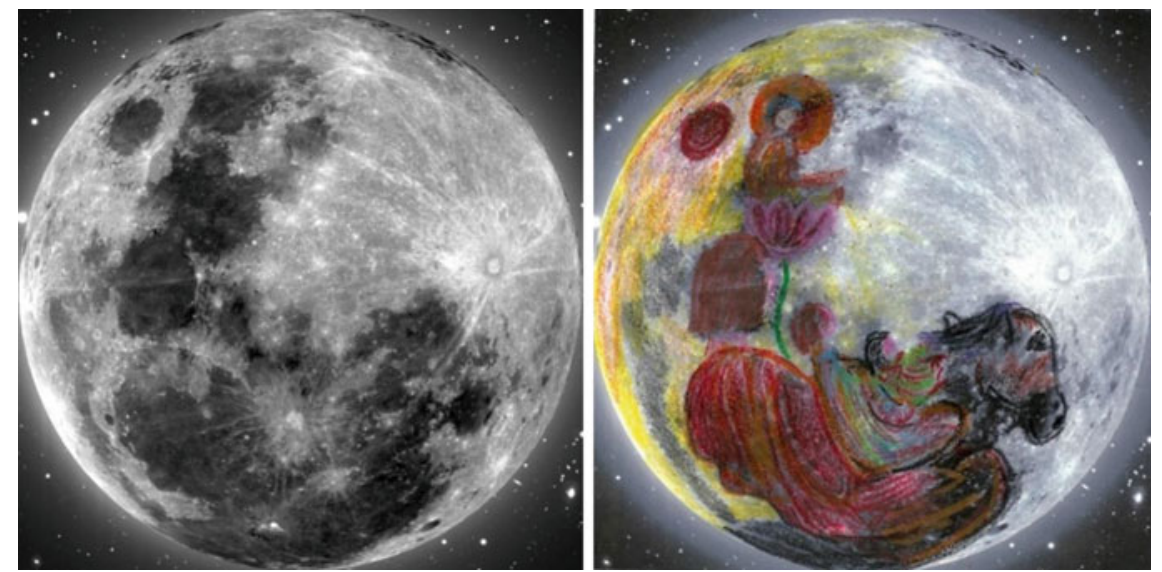

Fig. 6 Original image of the Moon (left), Perceived image samsāra (right)

Buddha was pointing to on the Moon in the context of His sermon, in which He describes his path to enlightenment.

There is no path to discoveries. It happens in unexpected ways. For brevity, details of the discovery are left out, and the reader is referred to a blog posting referenced in the Footnote. ${ }^{7}$ The finding highlights the connectedness of all beings on Earth, and that everything we feel and experience in some form or the other gives us the strength and courage to sustain and strengthen the conditions of life on Planet Earth. Some excerpts from the blog are reproduced here for completeness.

Briefly, all NASA manned and robotic missions carried out thus far in Lunar exploration have used vertical landing as the means to land on the Lunar surface. Moon's gravity is one-sixth Earth gravity, and the lunar environment is in the vacuum of space. Because there is no environment on the Moon, aerodynamic drag does not exist to enable parachutes to slow down the descent. There is no other way for humans to land on the Moon safely other than to land vertically with rocket thrusters. Rocket propulsion is the only option. How about transporting cargo to the Moon and the possibilities for reducing the cost without rocket propulsion?

During the Summer of 2007, while engaged in a NASA fellowship at the Jet Propulsion Laboratory, there were many discussions of cargo transportation addressing the planned Lunar Outpost. Of course, the cost of transportation was a critical issue. Using inflatable objects to land safely on Mars had already been tested and proven. So, with a mission to deploy an Earth-observing telescope, an idea was conceived to land an inflatable ball-shaped robot on a curved rolling surface in much the same way as a plane lands on an airport runway. It would be a bowl-shaped rollway instead of a runway. Mathematically speaking, the bowl-shape had to satisfy the Lyapunov criteria for stability. All that had to be done immediately upon touchdown was

${ }^{7}$ http://sun-faced-buddha-moon-faced-buddha.blogspot.com/2011/08/discovery-of-buddha-form. html. 
to deflate the ball in a controlled manner so it would slow down the rate of motion rapidly and allow the ball to deflate entirely upon reaching the target location and deploy the Earth-observing telescope. The question boiled down to finding a Crater with just the right characteristics that would enable such a robotic mission.

The Messier Crater, with its elliptical shape and the relatively smooth interior, offered the best possibility for landing a soccer-ball-shaped robotic object inside the crater. Located in Mare Fecunditatis, the Sea of Fertility, the Crater is known to have been formed over 3 Billion years ago. The idea was to let a ball-shaped robot to touchdown tangentially near the inside edge of the Messier Crater, roll towards the target location in a controlled manner, and deploy an Earth-observing telescope at the far end in the darkest spot on the Moon with a full view of Earth. The purpose of the telescope is to continuously observe Earth and beyond to detect near-Earth asteroids and serve as an early warning system against a threat from an asteroid collision. The mission would demonstrate the low cost of transporting cargo to the Moon. It would set the stage for commercial space cargo transportation, a necessary infrastructure towards the development of a Lunar habitat. It was just an idea then and is still a possibility for a future NASA mission. Figure 7 illustrates this concept.

The Craters reflect $99.9 \%$ of the incident sunlight and create rays of white light that point in the westerly direction (with Tycho as reference). The two beams of reflected UV radiation are mesmerizing. Figure 8 shows pictures taken during Apollo 15 and 17 missions and highlights the reflectivity of the crater interiors and the high energy beams that clearly show potential for a wide range of Lunar-based applications.

It is theorized that the impact of a comet or a meteor or an asteroid occurred at a low incidence angle $\left(<2^{0}\right)$, causing the formation of Messier A and then Messieranalogous to how a rock would skip the surface of the water if it were thrown at a low incidence angle. The high reflection coefficient of the interior of the Craters causes the cone of reflected light to shine brightly like a searchlight from the East to the West. Because there is no environment on the Moon, the rays of reflected light travel linearly over many kilometers of the lunar surface with no edge dispersion. The reflected light sources provide a means to navigate precisely to the location.
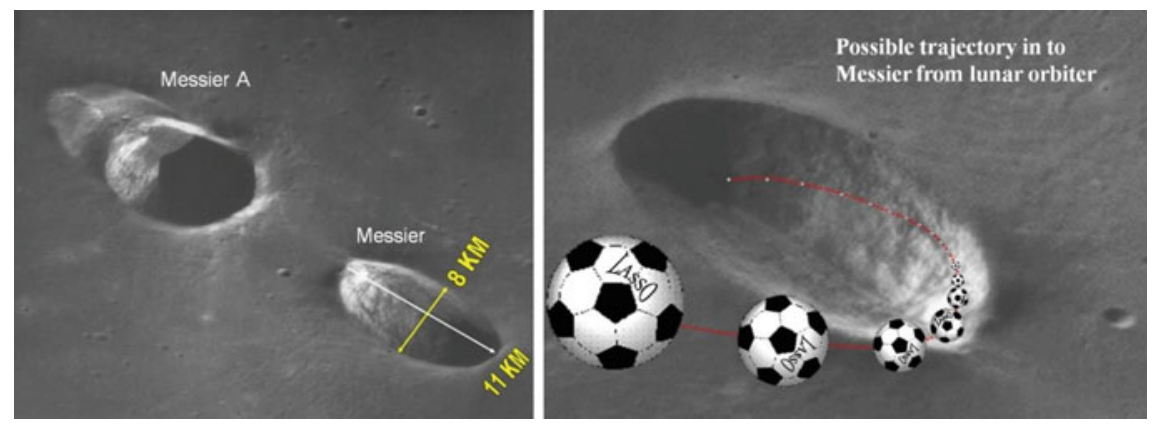

Fig. 7 Messier Crater pair (left). Deploying an Earth-observing telescope in Messier (right) 

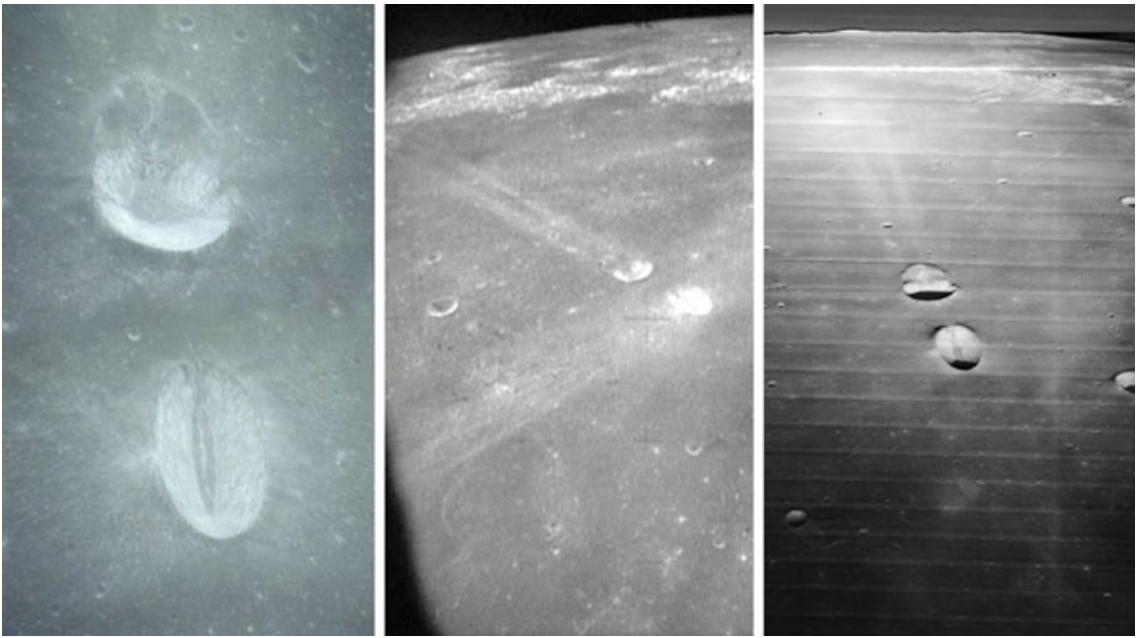

Fig. 8 Photographs from Apollo 15 and Apollo 17 missions: Messier A and Messier Lunar Craters show high reflectivity of the crater interior. The interior has a higher albedo than the surrounding Mare

Simple geometry using a straight edge and a protractor shows the regions from where the Messier rays may be visible to the naked eye. One could surmise that the cone of radiated light energy in the vacuum of space could cover all the Marias that are West of Mare Fecunditatis. The point here is that an observer located anywhere above the region covered by Marias Nubium, Cognitum, Insularum, Vaporum, Tranquillitatis, and Nectaris can see the point sources of light from Messier A and Messier. The convenience of using Matlab ${ }^{\circledR}$ image-processing functions to analyze the key features of the light patterns of high-resolution images of the Moon provided some degree of confirmation. There was a degree of truth to conjectures and speculative thinking. The premise that rays of light could give directional guidance for orbiting Lunar modules to eject cargo payload that will reach the Messier Crater and land safely appeared feasible. However, the cone of light formed by the reflected light sources from the Messier Craters and the countless number of craters causes an interference pattern above the Lunar surface.

In the course of examining ways to isolate the rays from Messier Craters from the interference pattern, out of the blues, a 3D holographic image of the Buddha form was discovered above Tycho, the South Pole of the Moon. My immediate thought was: Could this be the answer to what The Buddha pointed to the Moon? It is indeed ironic that one could stumble into something so different, unique, and relevant and in an unexpected way.

The image is composed of all wavelengths in the electromagnetic spectrum. The holographic image is located within the region enveloped by Marias Nubium, Cognitum, and Insularum on the left, Mare Vaporum at the top, and Marias Tranquillitatis 
and Nectaris on the right. The face of a human form is located just below Maria labeled "Mare Vaporum" in Fig. 9.

The holographic image is perceived to be formed by directed radiation crisscrossing the lunar surface from multitudes of lunar craters that span the regions enveloped by Marias Nubrium, Cognitum, and Insularum on the left, Mare Vaporum on top, and Marias Tranquillitatis and Nectaris on the right. These are point sources of reflected UV radiation in addition to the radiated beams from the Messier Craters

Figure 10 illustrates the Full moon in visible light and a false-color image taken by the Galileo spacecraft from approximately 425,000 km from the Moon. The highlighted segment shows a discernible object.
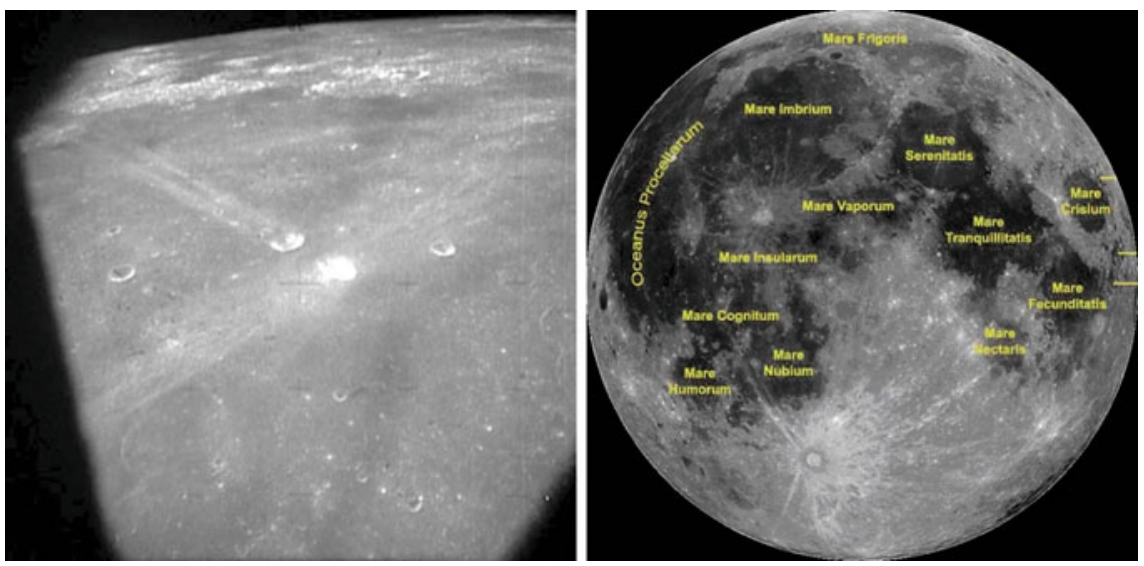

Fig. 9 Messier Craters, Mare Fecunditatis, from Apollo 15 mission. Location of Lunar Marias showing an image representative of the Abhaya Mudra
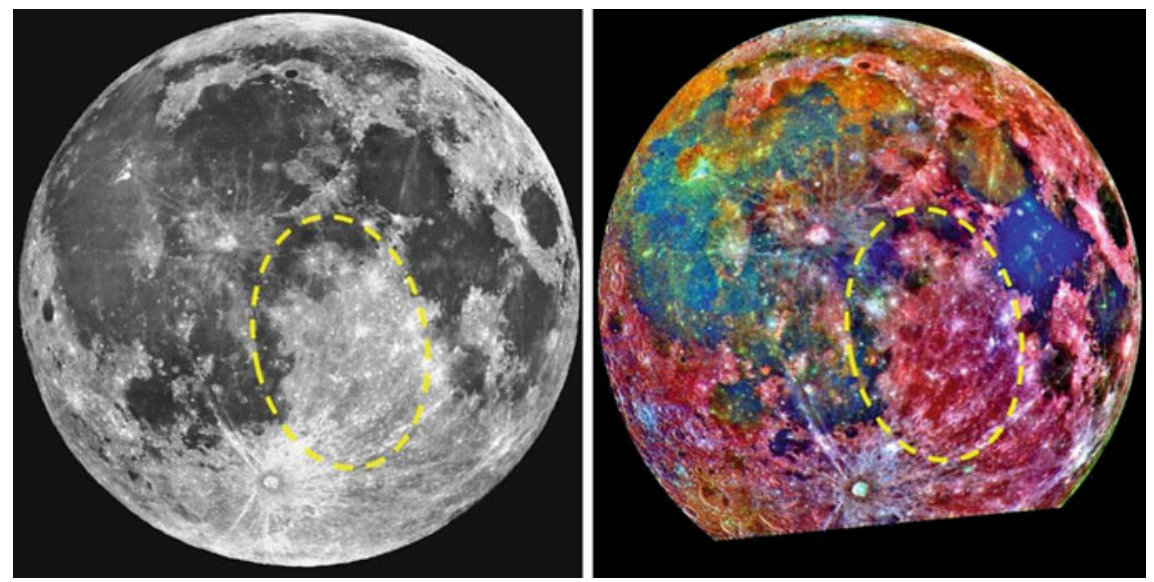

Fig. 10 Location of the Buddha form at full-scale shown above Tycho 

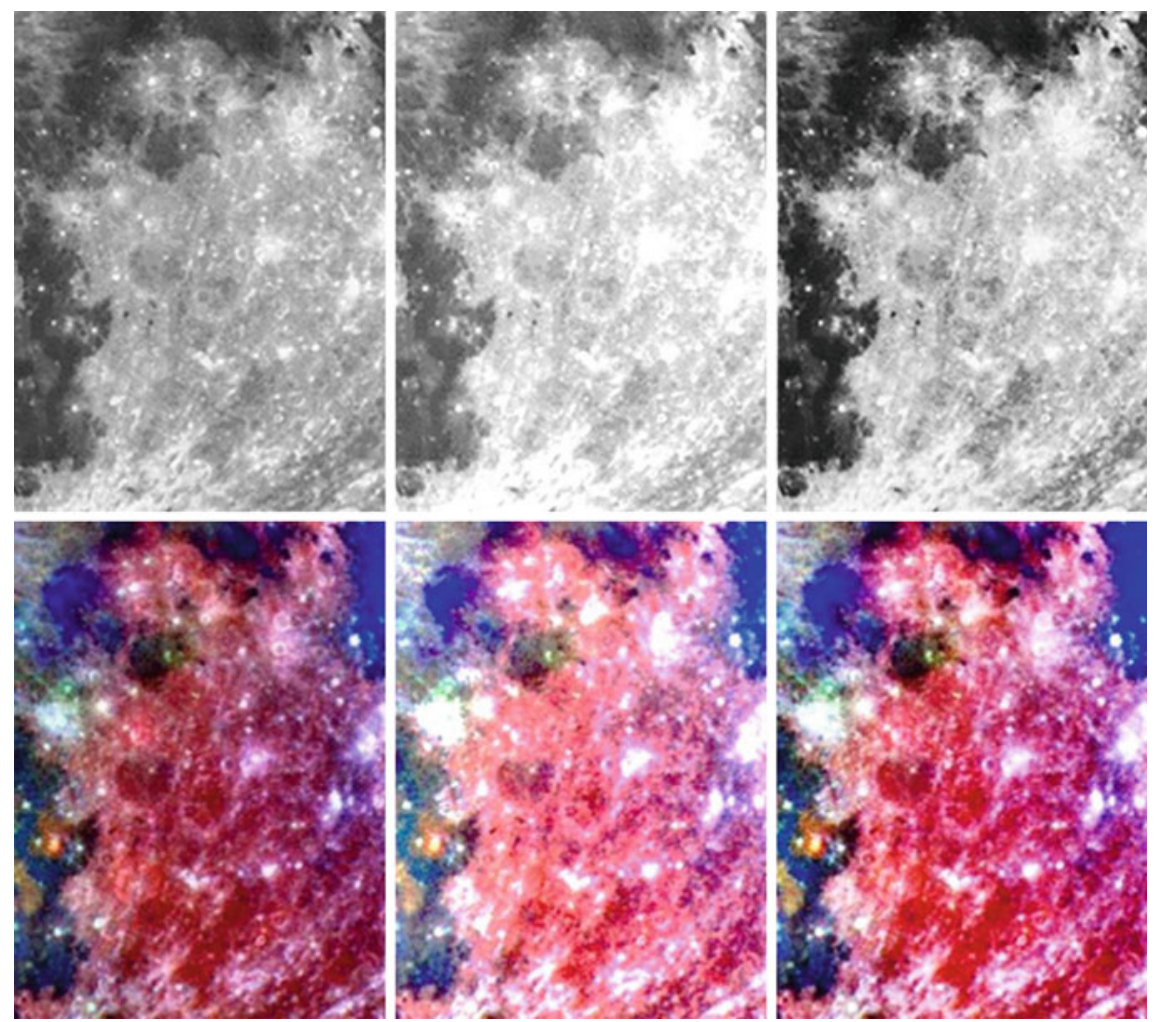

Fig. 11 View of the image at different contrast shows the posture of the Abhaya Mudra form

A closeup of the image formed in visible light and a false-color image is illustrated in Fig. 11 at different contrast levels to aid in identifying the 3D image.

Figure 12 is a further close-up of the 3D holographic image near the facial area. It shows how legendary knowledge of the horrifying character described as Mara may have appeared within the mental formations of The Buddha.

Figures 10,11, and 12 points to the location and distinct features of the holographic image on the Moon. Images in visible light and those in false colors are shown with slightly different contrast levels to enhance the viewing experience and aid in feature identification. Figure 12 shows the facial characteristics in what appears to be a composite image of a human face with a mask that partially covers the top half of the human face. By deduction, one may conclude the foreground is the face of Mara, the evil King with his crown and intimidating mustache. Mara's face masks part of the human face. We must contend with the pixel resolution of the human face behind the mask. It is interesting that the shade of grey-green clearly distinguishes the hologram of what appears as the form of a human with the right ear fully visible. Part of the right side of the head, the chin and mouth, are also easily distinguishable 

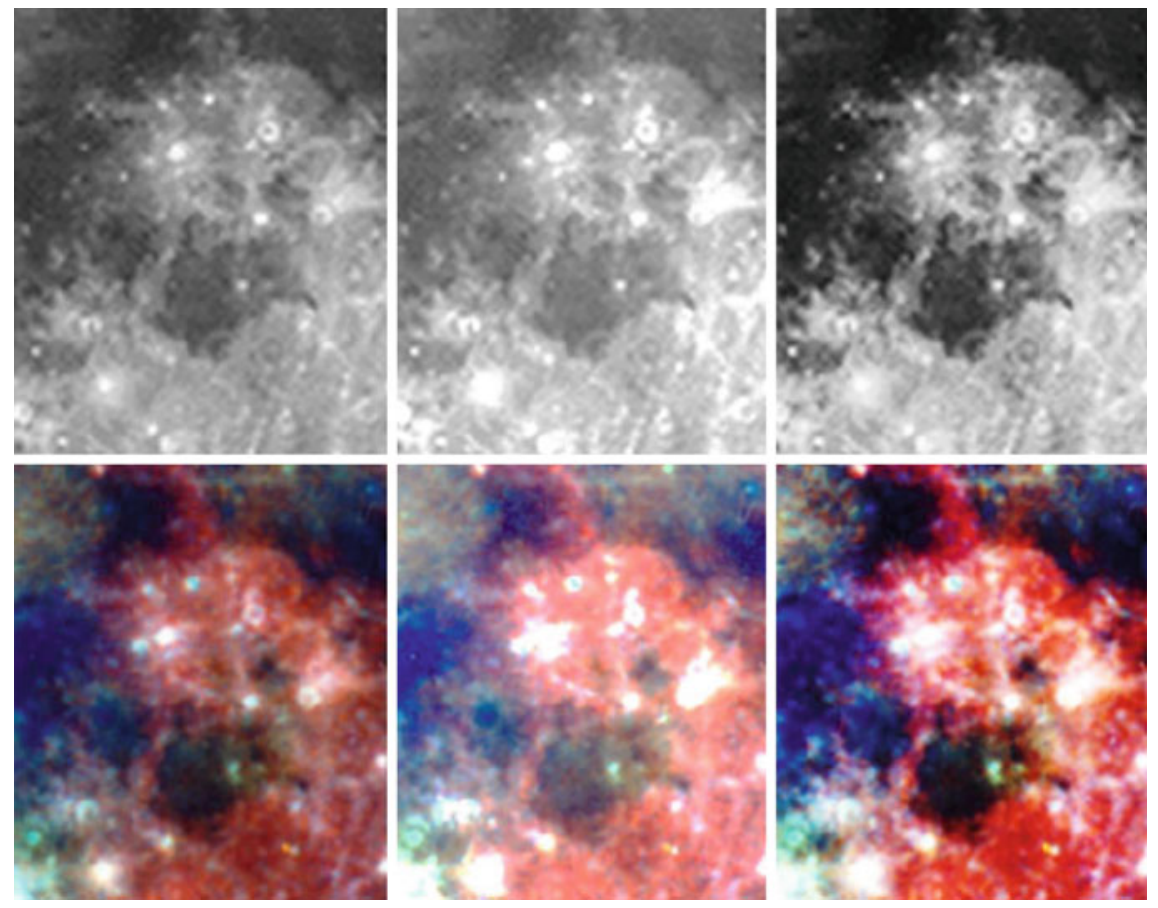

Fig. 12 Close-up of the face at different contrast shows the right ear, mouth, and chin of a humanlike face, which appears Green in the false-color image. A demonic face-mask covers the eyes and the forehead in Red, showing a crown, a prominent nose, and grotesque mustache of Mara, the evil

in grey-green. The right shoulder is recognized by tracing upwards from the right palm. $^{8}$

What is the significance of this finding? If The Buddha was indeed pointing to the image, then what is the message that He wished to convey to humanity? How could He have perceived or seen such an object with his naked eyes? Observing the finger provides no information while what is on the Moon is many more than one can imagine. His battle of wits with Mara, as described in the literature, is consistent with details in the Bhavachakra. The three-dimensional holographic image, which is an epitome of His enlightenment, exemplifies the battle of wits in a singular and eternal shape and form on the Moon.

The rhythm of the Moon's phases has for time immemorial guided humanity in developing the pillars of religions and the ethical and moral guidelines that foster the beliefs in the existence of Gods and demi-Gods in their abstract forms, and Saints who have lived in flesh and blood to provide the inner strength and wisdom. Gautama Buddha, as a human, understood human intolerance as an outgrowth of ignorance and desire, which is the root cause of all the pain and suffering.

\footnotetext{
${ }^{8}$ The images of the Moon are obtained from the NASA website: https://solarsystem.nasa.gov/ resources/2460/lunar-near-side/?category=moons_earths-moon.
} 
In closing, one could surmise that the intent in pointing to the Moon is to unlock the doors of the human mind and arouse the consciousness of humanity at its roots to build a mindset towards tolerance, confidence, fearlessness, mindfulness, and compassion. We may perceive the message to mean that a human is always under the grip of a force that, if unrecognized, can lead to a path of self-destruction. The symbolic representations in the Bhavachakra epitomize the paths one can lead in their life. The findings are at the tip of an iceberg leaving much more to be explored and understood. Of course, as humans explore the Moon, it is likely the shapes and forms we know now will not remain the same, raising issues of how humans contribute to the impermanence. Exploration requires one to leave things behind the way you find it so the future generations can experience, understand, and develop a mindset for positive change.

On Earth, while one can perceive a zero-Carbon environment with Solar, Wind, and Water alone and nothing else, the realities are that humans will continue the use of fossil fuels unless and until the cost of electric power consumption is a fraction of a cent per kilowatt-hour. Although we know it will happen sometime in the future, it leaves one to perceive the future and the reality that may exist then.

As health and wellness are a significant aspect of our daily life, Ayurveda is a discipline that I have adopted to practice. Our perceptions of healing come from a belief that herbs of all types had to have been the only remedial elements of the ancient apothecary. We may, therefore, perceive the adoption of Ayurvedic medicine as a complementary form to modern medicine that helps to moderate the mind and body to stay healthy and fit.

\section{Epilogue}

Professor Hung T. Nguyen is among the greatest mathematicians of our times who has made an everlasting impact on my life and others close to me, and on the lives of many of his students who I know very well. Enjoying life in the beautiful surroundings of Chiang Mai, Thailand, his presence is felt across the globe. Hung is truly an epitome of what General MacArthur said in his departure address to the US Congress more than a half-century ago in 1951, stating, "old soldiers never die, they just fade away." $\mathrm{He}$ is indeed a great inspiration to anyone considering retirement. Retire, but don't disappear. It is a challenge that shows commitment to advancing knowledge to the highest degree regardless of where you are or what you are doing.

Hung Nguyen's seminal contributions to the Theory of Random Fuzzy Sets embodies everything one can imagine. It applies to all disciplines, including engineering, economics, environmental science, natural sciences, physical science, social sciences, and medicine. With all things considered fuzzy, our interactions were driven from an engineering perspective to integrate fuzzy information to the control of real-World physical processes and systems. Hung's contribution to the mathematical foundations of statistical and fuzzy inferencing, data fusion, large data analysis, 
sampling, filtering, clustering, image analysis, anomaly detection, and for estimation, prediction, and control, greatly influenced our explorations in Control Theory. Modeling ambiguity and uncertainty, present in virtually every aspect of human decision-making, had become a primary focus of our research in the area of threat assessment, analysis, and threat mitigation.

During a trip to Bhubaneswar, India, in 1998, we visited the City of Puri, a historically famous city and known for the Jagannath Temple, a temple that every Hindu believes must visit at least once in their lifetime. Before arriving in India, Hung had asked me if we could go to a place where he could see Indian Buddhist monks practicing Buddhism, and I was searching for places to visit. Although there are many Hindu temples all across India, I was not sure where to find one that was in our travel plans. For instance, many monasteries and numerous Buddhist temples and pagodas dot the landscape in every city and town in Thailand and Vietnam, and I was looking to visit a Buddhist monastery in India. I had never been to one in India. As we approached the entrance of the Jagannath Temple, a temple administrator without saying a word, and chewing a mouthful of beetle-nut and leaves, pointed his finger at a sign on the wall that read "Hindus Only." I knew Hung is a Buddhist, and I am a Hindu, and I thought, does it mean I can go in and Hung cannot? Looking at me, the temple administrator said in Hindi that he would permit me inside but not Hung. Confused at first, I told the administrator that Hung was a Buddhist. But the administrator insisted in Hindi and pointing to the sign that said Hindus Only! Surprised and still not satisfied with his answer, I asked him why he would not let a Buddhist in, the administrator's reply was stunning. He said, "Even India Gandhi, the Prime Minister, was not allowed in because her husband Feroze Gandhi was a Muslim." But here is the irony.

Buddhism is an offspring of Hinduism. At the entrance to any Hindu temple, there is a pillar called Ashoka Pillar, named after King Ashoka the Great, who adopted and practiced Buddhism during the time of his reign between 273 and 236 BCE. King Ashoka, a devout follower of Buddhism, called it the Buddha Stupa, only about 300 years following the historical Buddha. The Buddha Stupa symbolizes the metaphysical transfer of knowledge and wisdom from all higher-level deities (Gods and Goddesses in the Hindu mythology) through The Buddha, giving meaning to human contact with all other human beings entering the deity's abode. In other words, the notion of transfer of energy from higher-beings to ordinary human beings is through The Buddha. Knowing that every Hindu temple has a representation of The Buddha, the refusal to let Hung enter the temple seemed conflicting. The administrator had perhaps failed to recognize that the Buddha Stupa stands as a bridge between all humans and God. Or maybe, he was obeying orders as dictated by the signposted message on the wall. It was an overwhelming feeling to realize that knowledge exists, and one must find it. I even asked the temple administrator how he would know that I was a Hindu just by looking at my appearance. Of course, his reply in Hindi was, "You look Hindu." Although his guess was right, my physical looks at that time could also have misled their perceptions that I was not a Hindu! At our next stop in Delhi during the same trip, a pious-looking individual sitting on the steps of Jama Masjid, a famous 16 th Century mosque, while staring at my grey and white beard asked 
in Hindi “Are you Muslim?". I was intrigued by the manner and the circumstances under which it happened. There appeared to be some form of a fitness function in identifying religious affiliation based upon a perception of an individual's persona, the color of the skin, the shape of the eyes, height and other stigmas that give the means for biometric identification. Many such thoughts deeply inspired me towards engaging in perception modeling, a topic that shaped my research with Hung following the September 11, 2001, terrorist attack. Of course, the realities then and the realities now are far different. The consequences of technology must be perceived in light of a shift in the human mindset.

As a colleague and a close friend, Hung motivated me, inspired me, and advised me on life-changing matters. During his tenure at New Mexico State University, we engaged in research and teaching for over three decades [4, 5]. Hung brought to light many mathematical tools required in decision-making in ways that an engineer could understand. He has had a transformational effect on my life and many others. It is indeed an honor knowing him for all these years.

\section{References}

1. M.M. Cohen, Tulsi-Ocimum sanctum: a herb for all reasons. J. Ayurveda. Integr. Med. 5(4), 251-259 (2014), https://www.ncbi.nlm.nih.gov/pmc/articles/PMC4296439/

2. A. Guruge, The Buddha's Encounters with Mara the Tempter: Their Representation in Literature and Art, https://www.accesstoinsight.org/lib/authors/guruge/wheel419.html

3. C. Shannon, A mathematical theory of communication. Bell Syst. Tech. J. 27, 379-423, 623-656 (1948)

4. H.T. Nguyen, N.R. Prasad (eds.), Fuzzy Modeling and Control: Selected Works of M. Sugeno (CRC Press, Boca Raton, 1999)

5. H.T. Nguyen, N.R. Prasad, C.L. Walker, A.E. Walker, A First Course in Fuzzy and Neural Control (CRC Press 2002) 